\section{Nasal prosthesis after partial rhinectomy. A case report}

\author{
Shekhar Gupta, ${ }^{1}$ Bharti Gupta, ${ }^{2}$ \\ Bhagwandas K. Motwani ${ }^{3}$ \\ ${ }^{1}$ Department Of Prosthetic Dental \\ Science, College of Dentistry, Jazan \\ University, Jazan, Saudi Arabia; \\ ${ }^{2}$ Department of Maxillofacial Surgery \\ and Diagnostic Sciences, Division of \\ Oral Pathology, College of Dentistry, \\ Jazan University, Jazan, Saudi Arabia; \\ ${ }^{3}$ Department Of Prosthodontics, \\ Swargiya Dadasaheb Kalmegh Smruti \\ Dental College \& Hospital, Nagpur, \\ India
}

\begin{abstract}
Maxillofacial defects can result from several reasons, including neoplasia, congenital malformations, trauma, oral infections, etc. This kind of defects can be severely debilitating to the patients. To improve the quality of life of these patients, the options include surgical reconstruction and maxillofacial prosthesis. However, surgical approaches have many inherent disadvantages and limitations. This case report describes the prosthetic rehabilitation of a female patient who underwent partial rhinectomy secondary to basal cell carcinoma. The case was planned with a silicone prosthesis with anatomic and spectacle retention. A non-surgical method of rehabilitation was followed owing to the patient's choice and financial constraints. The final prosthesis was aimed at enhancing the esthetics and function of the patient, thereby improving her quality of life.
\end{abstract}

\section{Introduction}

Neoplasia of the head and neck region profoundly affect patients' quality of life, as they are severely disfiguring and a constant reminder of the affliction. These cancers are emotionally debilitating to patients and their families. ${ }^{1,2}$ Malignancies of the nasal septum are relatively rare and account for only $9 \%$ of all cancers of the nasal cavity. ${ }^{3,4}$ The surgical resection of the cancerous tissues most often results in significant morphologic disfigurement and psychosocial estrangement of the patient. ${ }^{5}$ It is of paramount importance to provide appropriate rehabilitation treatments for patients with facial defects to improve their quality of life. ${ }^{5-7}$
Furthermore, there are basically two treatment modalities available for maxillofacial defects, that is, surgical reconstruction and prosthetic rehabilitation or a combination of the two. ${ }^{8-11}$ In particular, surgical reconstruction of maxillofacial defects is often challenging to perform from a technical point of view. Additionally, surgical reconstruction is associated with a long recovery time, risk of complications, increased cost and it seldom leads to patients' satisfaction. ${ }^{8,10}$

Maxillofacial prosthodontists have several options available to rehabilitate patients using prosthetic restorations to improve function and aesthetic. ${ }^{11}$ An aesthetic and comfortable maxillofacial prosthesis alleviates many concerns of the patient and improves their quality of life without the risks associated with surgery. ${ }^{8}$ The choice of nasal prosthesis is dependent on the site, size, age, etiology, severity, and patient's desire. ${ }^{12}$ A nose prosthesis is esthetic and provides the respiratory function. Also, a prosthesis offers the clinician and the patient the means to observe the healing wound for recurrence of disease. ${ }^{5}$

The purpose of this case report is to describe a custom-made silicon nasal prosthesis with anatomic and spectacle retention after partial rhinectomy due to carcinoma.

\section{Case Report}

A 28-year-old female patient was referred from the Department of oral and maxillofacial surgery for the nasal prosthesis to the Department of Prosthodontics Sharad Pawar Dental College, Sawangi (Megeh) Wardha. Maharashtra, DMIMS University.

The patient had a history of basal cell carcinoma involving the nose which was treated using a partial rhinectomy six months ago. The nasal bones and the bridge of the nose was spared in the resection(Figure $1 \mathrm{~A}$ and $\mathrm{B}$ ).

During the examination, the patient expressed various esthetic concerns and a desire to improve her facial appearance. The different available prosthetic treatment options, including acrylic resin nasal prosthesis, implant retained silicone prosthesis were discussed with the patient. Based on the discussion, the patient chose a nasal prosthesis made of silicone. The case was planned for silicon nasal prosthesis with anatomic and spectacle retention.

The patient was draped, the necrotic tissue was debrided, and a healing impression was made for facial moulage.

Petroleum jelly was applied to the patient's eyebrows and eyelashes to avoid
Correspondence: Shekhar Gupta, Department Of Prosthetic Dental Science, College Of Dentistry, Jazan University, Jazan, Saudi Arabia.

E-mail: drshekhar786@gmail.com

Key words: Nasal prosthesis; rhinectomy.

Consent: Patient consent was obtained for publication of clinical photo's.

Received for publication: 4 Septemer 2019.

Accepted for publication: 20 March 2020.

This work is licensed under a Creative Commons Attribution NonCommercial 4.0 License (CC BY-NC 4.0).

(C) Copyright: the Author(s), 2020

Licensee PAGEPress, Italy

Clinics and Practice 2020; 10:1200

doi:10.4081/cp.2020.1200

the sticking of the impression material. Wet gauze was packed into the defect to prevent the flow of material into the undesired areas. To minimize tissue bed distortion, an impression was made of the defect and adjacent tissues using a Hydrophilic vinyl polysiloxane light body elastomeric impression material (Make Reprosil Tubes Standard Light Body, Dentsply Caulk) in a custom tray in a semi-upright position (Figure 2A and B).

The cast was then poured with the type III dental stone.(KALSTONE, Kalabhai Karson Private Limited, MUMBAI INDIA) (Figure 2C).

A heat cure clear acrylic (DPI HEAT CURE MUMBAI, INDIA) stent was made as a base of the prosthesis to engage the decided undercut and for the mechanical attachment of silicon to the base.(Figure $3 \mathrm{~A})$.

A wax model of the prosthesis was carved on the cast with dental modeling wax (DPI, MUMBAI, INDIA). The contours of the prosthesis were modified based on the patient's general appearance and preoperative photographs.

The wax pattern adaptation on the patient's faces was checked, especially in the border areas (Figure 3B and C).

After patient consent, the wax pattern was flasked routinely.

After the de-waxing procedure, shade selection was done in the morning time, and room temperature vulcanizing silicone (RTV 1556 Factor II Incorporated U.S.A) was packed in the mold for curing.

The finished prosthesis was trimmed, and spectacles were used for additional retention and to mask the margins of the 
prosthesis. A nose pin was added to the ala of the nose at patient's request (Figure 4A).

The prosthesis was delivered to the patient after demonstration of placement of the prosthesis (Figure 4B). Detailed instructions were given regarding care and use of the prosthesis.

The first post-insertion adjustment was scheduled the next day after the insertion to ensure the health of the underlying tissues. At the follow-up evaluation after four weeks, the prosthesis appeared to be functioning within normal limits. A patient satisfaction questionnaire indicated the patient's contentment with the prosthesis. The patient was recalled every three months for evaluation.

\section{Discussion}

The present case reports the fabrication of a custom-made nasal prosthesis for patient rehabilitation post a partial rhinectomy due to basal cell carcinoma. The prosthetic rehabilitation aims at improved function and esthetic of patients with facial deformations resulting in considerable cosmetic impairment. Surgical reconstruction in such cases is generally technically demanding and often leads to unsatisfactory results. ${ }^{13,14}$ On the other hand, facial prostheses enable early recuperation as well as allow periodic inspection of the site, eliminate hospitalization, lower treatment cost and help in the patients' timely psychosocial rehabilitation. ${ }^{15}$

Newer materials for maxillofacial prostheses include vinyl plastisols, PMMA, polyurethanes, latex, and silicone elastomers. ${ }^{16}$ Silicone elastomers have several advantages such as chemical inertness, strength, durability, simplified fabrication process, optimal esthetics, lightweight, and enhanced retention and stability due to the presence of flexible projections that can engage minor tissue undercuts., ${ }^{3,17}$ Accordingly, silicone was the material of choice in the present case.

Facial prostheses are not devoid of limitations, which include inadequate retention, colour change, patient rejection, and skin reactions due to adhesives. Nonetheless, patients' acceptance of facial prostheses can be improved drastically by improving aesthetics, retention, and stability of the prostheses. ${ }^{18,19}$ Retention of the nasal prosthesis has been achieved with attachment to endosseous implants, adhesives, undercuts or specatcles. Mechanical retention obtained by anatomic undercuts is the most desirable as these are noninvasive, biocompatible, esthetic, comfortable to use, and easy to fabricate and clean. ${ }^{5,20,21}$ Hence, in the present case, prosthesis with anatom- ic and spectacle retention was planned.

Furthermore, it has been extensively opined that a postoperative healing period of 3 to 5 months may be required before commencing fabrication of a definitive nasal prosthesis to allow for contraction and organization of the tissue bed. ${ }^{5}$ Additionally, literature also indicates the removal of nasal bones in surgical resection of the nose even if they are unaffected by the disease. ${ }^{4}$ However, in the present clinical case, the nasal bones and adjoining soft tissues were intentionally left intact to aug- ment the support of the spectacles at the bridge of the nose and to increase skin surface contact thereby strengthen the retention of the prosthesis. Also, minimizing the load on the prosthesis increases retentive time the patient can enjoy and prevents frequent replacement of adhesives. ${ }^{1}$

A challenge that a clinician faces while fabricating a maxillofacial prosthesis is obtaining a proper skin color match. A skin color match is achieved by adding suitable pigments to translucent silicone elastomers until an acceptable color match under

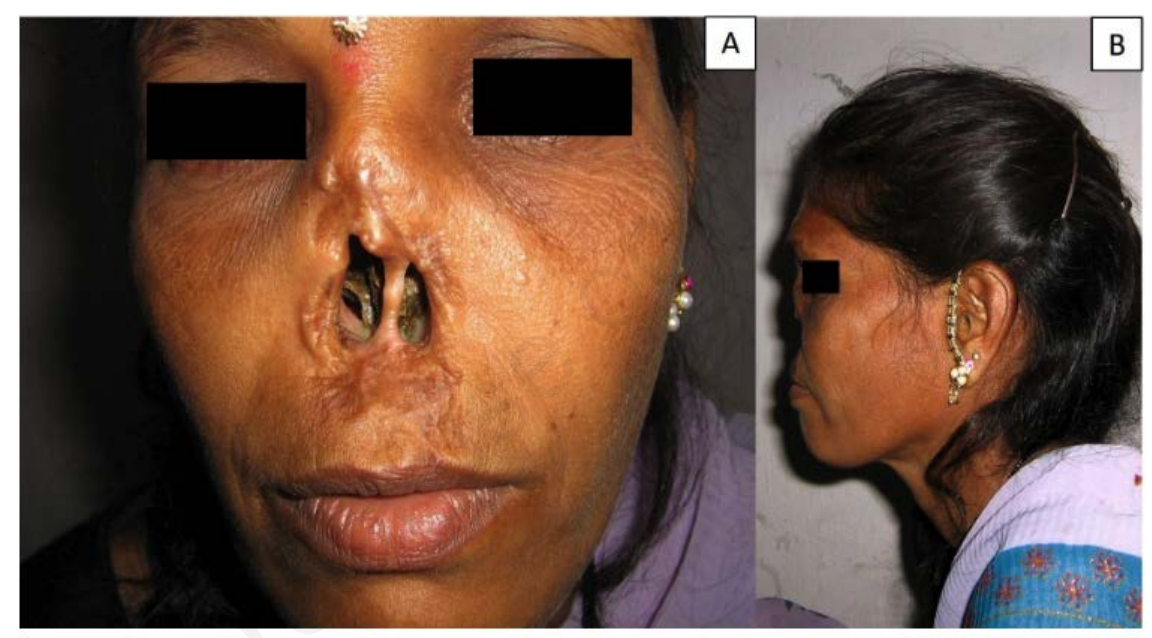

Figure 1. A) Post-operative frontal view; B) Post-operative lateral view (clinical photo published with patients permission).

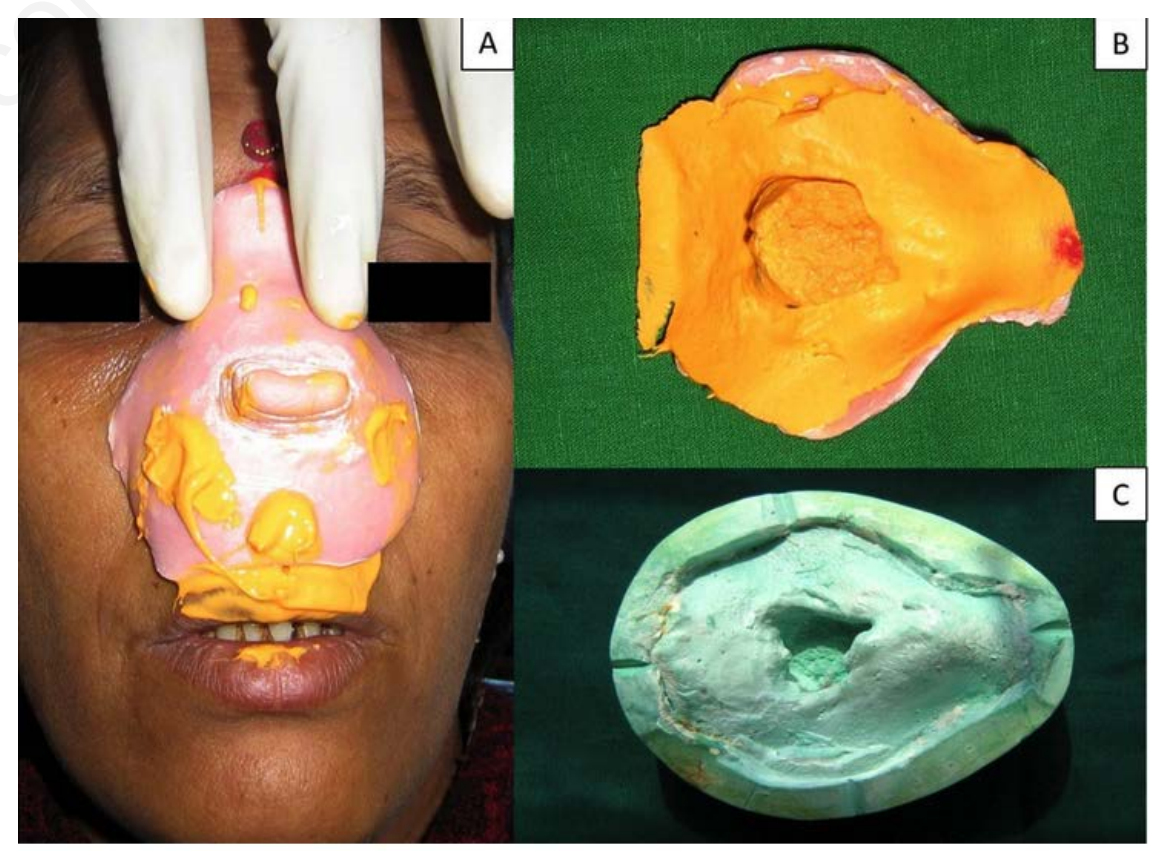

Figure 2. A) Final impression being taken; B) Intaglio surface of the final impression; C) Master cast (clinical photo published with patients permission). 


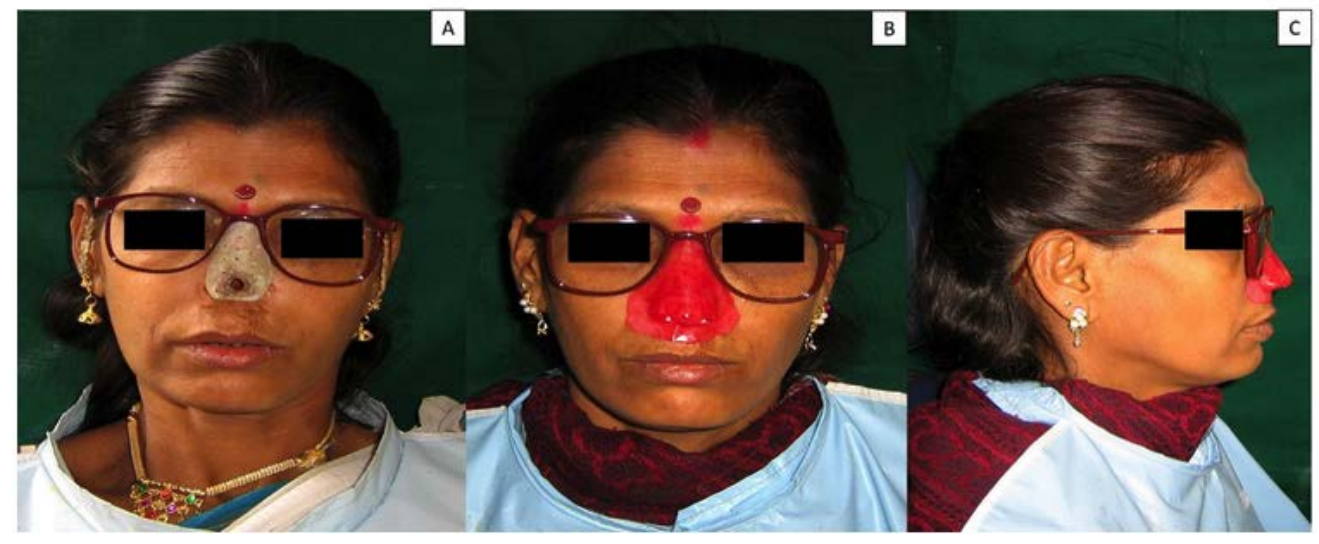

Figure 3. A) Acrylic stent trial; B) Wax up trail frontal view; C) Wax up trial lateral view (clinical photo published with patients permission).

(preferably) daylight is attained. ${ }^{8} \mathrm{~A}$ similar procedure was followed in the current case report.

Likewise, another essential property of facial prosthetics is longevity. The primary reasons for the replacement of facial prostheses are degradation and discoloration of the material. Literature reports the replacement of facial prostheses every 1.5 to 2 years, which can be a considerable burden to the patient. ${ }^{8,22}$ Hence, this area that needs attention in current and future research.

An ideal prosthesis should simulate the missing facial contours as accurately as possible, thereby allowing the patients to appear in public with confidence. This approach applies both final as well as interim prostheses because patients might greatly benefit from such a prosthesis when surgical repair not possible. A comprehensive and high-quality rehabilitation can dramatically improve patients' quality of life..$^{8,23}$ However, it is advisable that patients also receive counseling when provided with a facial prosthesis to learn to cope with their prosthesis.

Recently, CAD/CAM (computer aided design and computer aided manufacturing) system for the design and fabrication of maxillofacial prostheses has been introduced. However, its application is limited owing to its technical complexity, high expenditure, and unavailability at many centers. ${ }^{5,8,24}$ Nevertheless, the field of maxillofacial prosthetics is evolving and advancing rapidly in a quest to improve the quality of the final product.

\section{Conclusions}

It can be inferred from the present case report that silicone is one of the most acceptable materials for the fabrication of maxillofacial prosthesis. A custom made

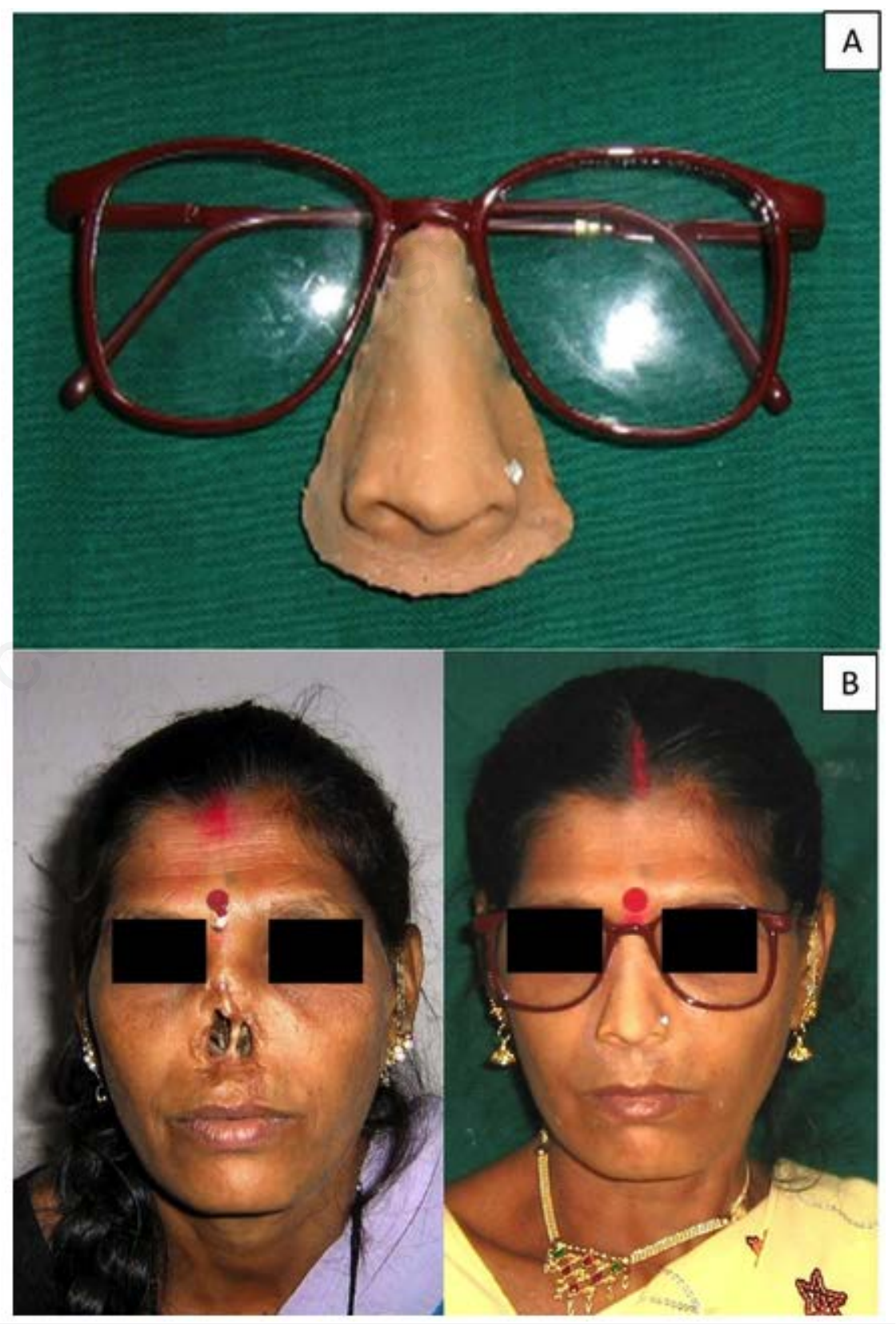

Figure 4. A) Final prosthesis with spectacles; B) Pre and post prosthesis comparison (clinical photo published with patients permission). 
nasal prosthesis can dramatically improve the appearance and the quality of life of patients with significant nasal defects associated with cancer.

\section{References}

1. Lemon JC, Kiat-amnuay S, Gettleman $\mathrm{L}$, et al. Facial prosthetic rehabilitation: preprosthetic surgical techniques and biomaterials. Curr Opin Otolaryngol Head Neck Surg 2005;13:255-62.

2. Gritz ER, Hoffman A. Behavioral and psychosocial issues in head and neck cancer. Maxillofacial rehabilitation: prosthodontic and surgical considerations. St. Louis;1996. pp 1-4.

3. Seilmis A, Oztucrk AN. Nasal prosthesis rehabilitation after partial rhinectomy: a clinical report. Eur J Dent 2007;1:115-8.

4. Jain S, Maru K, Shukla J, et al. Nasal prosthesis rehabilitation: A case report. J Indian Prosthodont Soc 2011;11:2659.

5. Qiu J, Gu XY, Xiong YY, Zhang FQ. Nasal prosthesis rehabilitation using CAD-CAM technology after total rhinectomy: a pilot study. Support Care Cancer 2011;19:1055-9.

6. Roumanas ED, Freymiller EG, Chang $\mathrm{TL}$, et al. Implant-retained prostheses for facial defects: an up to 14-year follow-up report on the survival rates of implants at UCLA. Int J Prosthodont 2002;15:325-32.

7. Guttal SS, Patil NP, Shetye AD. Prosthetic rehabilitation of a midfacial defect resulting from lethal midline granuloma - a clinical report. J Oral Rehabil 2006;33:863-67.

8. Ariani N, Visser A, van Oort RP, et al. Current state of craniofacial prosthetic rehabilitation. Int $\mathrm{J}$ Prosthodont 2013;26:57-67.

9. Wilkes GH, Wolfaardt JF. Osseointegrated alloplastic versus autogenous ear reconstruction: criteria for treatment selection. Plast Reconstr Surg 1994, 93:967-79.

10. Van der Lei B, Dhar BK, Van Oort RP, Robinson PH. Nasal reconstruction with an expanded forehead flap after oncological ablation: results, complications and a review of the English-language literature. FACE 1996;3:139-46.

11. Leonardi A, Buonaccorsi S, Pellacchia $\mathrm{V}$, et al. Maxillofacial prosthetic rehabilitation using extraoral implants. J Craniofac Surg 2008;19:398-405.

12. Ciocca L, Maremonti P, Bianchi B, Scotti R. Maxillofacial rehabilitation after rhinectomy using two different treatment options: clinical reports. J Oral Rehabil 2007;34:311-5.

13. Goiato MC, Pesqueira AA, da Silva CR, et al. Patient satisfaction with maxillofacial prosthesis. Literature review. J Plast Reconstr Aesthet Surg 2009;62:175-80.

14. Brent B. A personal approach to total auricular reconstruction: case study. Clin Plast Surg 1981;8:211-21.

15. Brenner P, Berger A. Epitheses of the face. Handchir Mikrochir Plast Chir 1992;24:88-92.

16. Andres CJ, Haug SP, Munoz CA, et al. Effects of environmental factors on maxillofacial elastomers: part I - literature review. J Prosthet Dent
1992;68:327-30.

17. Zemnick C, Asher ES, Wood N, Piro JD. Immediate nasal prosthetic rehabilitation following cytomegalovirus erosion: A clinical report. J Prosthet Dent 2006;95:349-53.

18. Goiato MC, AUR Fernandes, dos Santos DM, et al. Positioning magnets on a multiple/sectional maxillofacial prosthesis. J Contemp Dent Pract 2007;7:101-7.

19. Mancuso DN, Goiato MC, de Carvalho Dekon SF, Gennari-Filho H. Visual evaluation of color stability after accelerated aging of pigmented and nonpigmented silicones to be used in facial prostheses. Indian J Dent Res 2009;1;20:77-80.

20. Ethunandan M, Downie I, Flood T. Implant-retained nasal prosthesis for reconstruction of large rhinectomy defects: the Salisbury experience. Int J Oral Maxillofac Surg 2010;39:343-9.

21. Parel SM. Diminishing dependence on adhesives for retention of facial prostheses. J Prosthet Dent 1980;43:552-60.

22. Visser A, Raghoebar GM, Van Oort RP, Vissink A. Fate of implant-retained craniofacial prostheses: life span and aftercare. Int $\mathrm{J}$ Oral Maxillofac Implants 2008;23:89-98.

23. Klein M, Menneking H, Spring A, Rose M. Analysis of quality of life in patients with a facial prosthesis. Mund Kiefer Gesichtschir 2005;9:205-13.

24. Ahmed B, Butt AM, Hussain M, et al. Rehabilitation of nose using silicone based maxillofacial prosthesis. J Coll Physicians Surg Pak 2010;20:65-7. 